\title{
PHEROMONE BAITED TRAP FOR THE MANAGEMENT OF RED \\ PALM WEEVIL, Rhynchophorus ferrugineus F. (Coleoptera: Curculionidae) POPULATION IN COCONUT PLANTATIONS
}

\author{
C N K Rajapakse', N E Gunawardena ${ }^{2}$ and K F G Perera \\ I 4/I56, Clarence Rd, Indooroopilly, Qld 4068, Australia \\ 2 Department of Chemistry, University of Kelaniya, Sri Lanka
}

\begin{abstract}
4-methyl-5-nonanol (ferrugineol), the major component of the aggregation pheromone of Rhynchophorus ferrugineus $\mathrm{F}$. was evaluated as a lure for trapping of this pest in coconut plantations in Sri Lanka. Trap design, longevity of ferrugineol in field conditions, and the effect of trapping on damage incidence of $R$. ferrugineus were studied. N-pentanol, a known compound present in coconut stem volatiles was used in combination of ferrugineol in all tested traps. Trap designs tested were; an open plastic bucket, a funnel trap, and a modified metal trap. The open plastic bucket $(5 \mathrm{~L})$ baited with ferrugineol-pentanol, which was hung on coconut palm stem at 1.5 $\mathrm{m}$, caught significantly more number of adult weevils than ferrugineolpentanol baited funnel and metal traps. An open plastic bucket trap was six times less expensive than the metal trap currently recommended by the Coconut Research Institute, Sri Lanka. Ferrugineol remained effective as a bait for 12 weeks under field conditions. High capture rates of adult $R$. ferrugineus, were obtained in ferrugineol baited open bucket traps in plantations where the initial damage incidence was high. Monthly surveys of individual palms during pheromone trapping revealed that a sharp reduction of the number of coconut palms damaged by $R$. ferrugineus in 10-hectare experimental blocks. Continuous trapping of weevils with ferrugineol over a period of time significantly lowered the infestation of this pest.
\end{abstract}

\section{INTRODUCTION}

Red palm weevil, Rhynchophorus ferrugineus $\mathrm{F}$. is a serious pest of coconut palms in Sri Lanka. The estimated damage is a loss of about $10 \%$ of young palms in a severe infestation (Mahindapala, 1993). The larvae are responsible for damaging the palms and once they have gained access the death of the palm generally ensures (Nirula, 1956). If an infestation is detected early, trunk injection of monocrotophos $60 \%$ can be effective. 
Monocrotophos is banned in many countries and in Sri Lanka it is only allowed for use on coconuts and only in strictly limited quantities. If infestation is advanced the palm must be uprooted and burnt to reduce the possibility of infesting neighbouring palms. However, control of this pest is practically difficult because the migrating adult weevils from adjoining estates could re-infest the treated palms. Therefore, removing breeding sites and trapping weevils are potential strategies to control this pest. The Coconut Research Institute in Sri Lanka has recommended a metal trap baited with coconut petioles but the use of these traps has limitations. This was mainly due to the low trap catches associated with the trap and the frequent replacement of the bait. Evidence of male produced aggregation pheromones in palm weevils came from the observation of enhanced attraction of both sexes of the weevil, $R$. palmarum, to traps baited with palm stem and containing live males (Rochet et al., 1991). The male produced aggregation pheromone of $R$. ferrugineus was first identified and synthesised in 1993 (Hallet et al., 1993). It is a combination of 4-methyl-5-nonanol (ferrugineol) and 4-methyl-5-nonanone (ferugineon). Ferrugineol is highly attractive to weevils in the field, particularly in combination with a food source (Hallet $e t$ al., 1993).

The objective of this study was to develop an efficient method of trapping adult $R$. ferrugineus in coconut plantations using the major component of the aggregation pheromone, ferrugineol. In this study we examined a trap design to be baited with ferrugineol, the field stability of ferrugineol and the effect of pheromone trapping on the incidence of $R$. ferrugineus infestation in coconut plantations.

\section{MATERIALS AND METHODS}

Trap components: Ferrugineol was synthesized using a method established by Gunawardena and Bandarage (1995) and has $86 \%$ chemical purity. Glass capillary tubes constructed from the ends of pasture pipettes sealed at one end $(5 \mathrm{~cm} \times 2 \mathrm{~mm})$ were used as pheromone dispensers. Twenty-two $\mathrm{mg}$ of ferrugineol was filled into capillary tubes as a neat liquid. Ferrugineol was released from a capillary at a rate of $0.3-0.5 \mathrm{mg}$ per day under laboratory conditions. N-pentanol, which was believed to be present in volatile compounds evolving from wounded coconut bark and proved to synergise the activity of ferrugineol (Gunawardena and Herath, 1995) was used as an additive in all traps. Two glass capillaries filled with $22 \mathrm{mg}$ of each ferrugineol and pentanol were placed in a small plastic vial $(4.5 \mathrm{~cm} \times 1.5 \mathrm{~cm})$ for use in the trap. These capillaries were sealed after filling the chemicals and opened just after the installation of traps in the field. 


\section{Evaluation of trap designs}

Three trap designs baited with ferrugineol-pentanol were evaluated in two coconut plantations in Thummodara and Yakwila, reported to have red weevil infestations. These estates have young plantations of $10-20$ years and 150 palms per hectare. Ten-hectare blocks in each plantation were selected as experimental sites. Treatments were in completely randomized design with 3 replicates.

The trap designs used were; open bucket trap, funnel trap, and modified metal trap. Open plastic bucket trap consisted of $5 \mathrm{~L}$ plastic bucket filled with soap water up to $6 \mathrm{~cm}$. Pheromone dispenser was suspended on the rim of the bucket and a small-galvanized hood was fixed on the bucket over the bait to prevent rain water entering into the capillaries. Small holes were made on the both sides of the bucket at the height of $8 \mathrm{~cm}$ to over flow any excess water. The adult weevils lured by the bait falling into the bucket and drowned in the soap solution. Funnel trap consisted of a galvanized funnel (20 $\mathrm{cm} \times 9 \mathrm{~cm} \times 2 \mathrm{~cm})$ which was fixed to a plastic bucket $(5 \mathrm{~L})$. The pheromone dispenser was suspended on the inner surface of the funnel neck. The weevils lured by the bait slip through the funnel mouth, whose diameter is, less than the wingspan of an adult weevil so that the weevils trapped inside the bucket could not escape from the funnel. Trapped weevils were hand collected and destroyed. The third trap design used was a modified version of the trap currently recommended by the Coconut Research Institute (CRI) (Perera, 1990). In this trap a large galvanized funnel $(44 \mathrm{~cm}$ diam.) was fixed to a cylindrical wire cage $(80 \mathrm{~cm}$ height) which was then placed on a metal tray (44 cm diam.). The pheromone dispenser was placed in this metal tray.

The open plastic bucket and funnel traps were hung on coconut palms at $1.5 \mathrm{~m}$ from the ground while the modified metal traps were placed on the ground near coconut palms. The distance between two traps was $50 \mathrm{~m}$. Captured weevils in each trap were sexed visually and counted weekly for 3 months commencing from 30 May, 1995. Similar traps without the bait were used as checks.

\section{Comparison of traps: live males vs ferrugineol}

Modified metal traps baited with live male $R$. ferrugineus and pieces of coconut petioles were compared with the open plastic bucket traps baited with ferrugineol-pentanol and coconut petioles in a trial with 4 replicates. Live male weevils $(n=10)$ together with the 5 pieces of pealed coconut petioles $(6 \mathrm{~cm})$ were placed on the tray of the modified metal trap. In the open plastic bucket, ferrugineol-pentanol bait was suspended on the rim and 5 pieces of pealed coconut petioles treated with $1 \%$ carbofuran solution were 
kept inside the bucket. Hallet et al. (1993) has found that carbofuran did not interfere with the attraction of weevils on to coconut petioles. Coconut petiole pieces in both trap types were replaced at weekly intervals during the study period. Weevils captured in the traps were collected and counted weekly for over 8 weeks commencing from 5 May 1996. This comparison was made in 10-ha block within a 50-ha coconut plantation in Badalgama area for a period of 8 weeks commencing from 5 May, 1995.

\section{Field stability of ferrugineol}

Open plastic buckets were used as the standard traps to determine the field stability of ferrugineol and to optimize the capture rates. This experiment was conducted in each of 10-ha blocks in 4 different coconut plantations in Nattandiya, Thummodara, Dummalasooriya and Badalgama. Open plastic buckets baited with $22 \mathrm{mg}$ of ferrugineol were hung on palm stems at $1.5 \mathrm{~m}$ height and at a distance of $50 \mathrm{~m}$ between two traps. Number of captured weevils was collected, sexed and counted weekly until the pheromone was fully exhausted. Individual palms within the 10-ha blocks were surveyed for red weevil damage prior to trapping and at 1-month intervals during the trapping period. If the number of infested palms was 10 or above, the damage incidence was rated as very high. If the number of infested palms was 9-7, 6-4 and 1-3, the damage incidence was rated as high, moderate and low respectively. Soon after diagnosing an infested palm during the survey, it was treated with $10 \mathrm{ml}$ of $60 \%$ monocrotophos by trunk injection method in order to save the palm. But the palms that were beyond recovery were kept intact hoping the weevils inside would be lured into the pheromone traps. Surveys of individual palms were done continuously to check re infestation.

\section{RESULTS}

\section{Evaluation of trap designs}

Figure 1 shows the total number of adult female and male $R$. ferrugineus caught in three trap designs in Yakwila and Thummodara over 3month study period. Amongst the three trap designs tested, the open plastic bucket traps were significantly more effective for trapping the weevils in both experimental sites (ANOVA, $\mathrm{P}<0.0001$, Chi-square $=19.85$ (Yakwila) and 30.96 (Thummodara). Mean weevil counts in ferrugineol-pentanol baited traps varied considerably over the course of 3-month trapping period in both experimental sites. In Yakwila plantation, open plastic buckets caught $53.7 \%$ adult weevils during the 3-month time while funnel and metal traps caught $31.9 \%$ and $14.2 \%$ of weevils respectively. Similarly, in Thummodara study site, open plastic bucket, funnel and metal traps caught $52.4 \%, 31.7 \%$ and $15.8 \%$ of adult weevil respectively. 


\section{Yak wila}

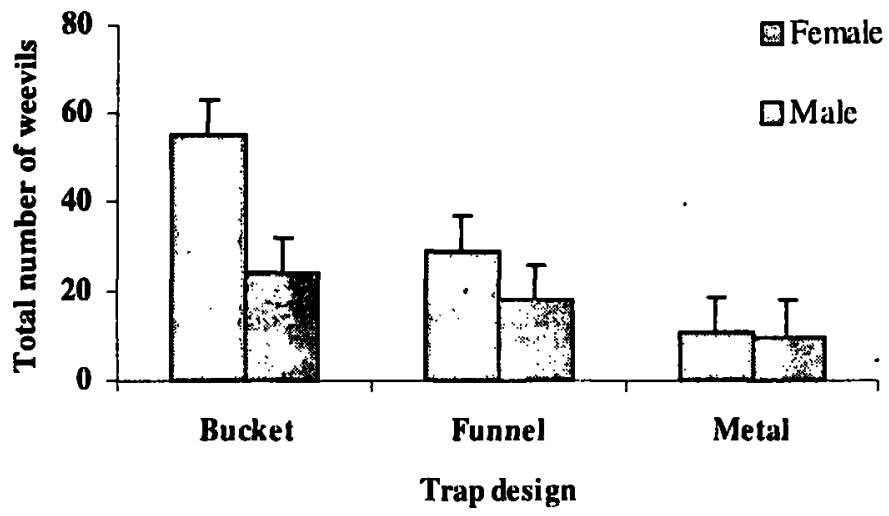

Thummodara

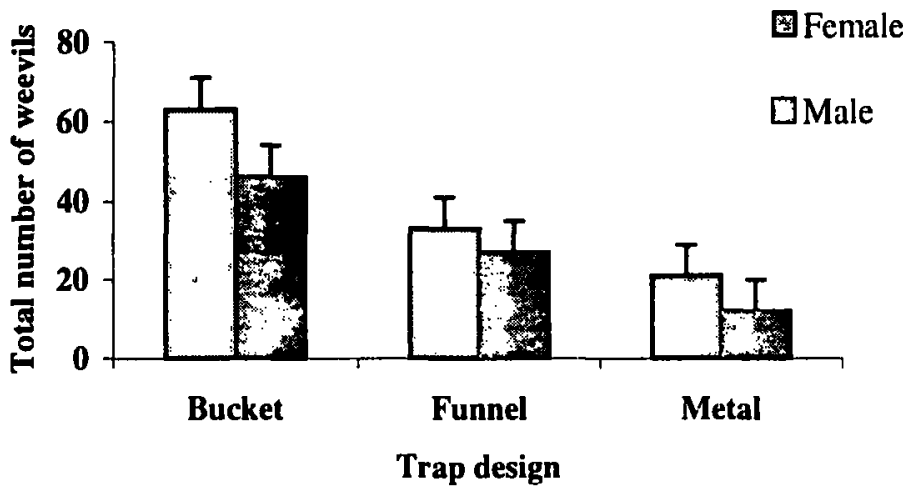

Figure 1: Total number of female and male red palm weevils caught in 3 types of pheromone traps in Yakwila and Thummodara sites for 3-month study period

Number of female weevils trapped in pheromone traps was significantly higher than the number of male weevils trapped (ANOVA, $\mathrm{P}<$ 0.01 , Chi-square $=6.67$ ). 


\section{Comparison of traps: live males vs ferrugineol}

No significant difference was observed between the number of adult weevils captured in the pheromone and coconut petiole baited plastic bucket traps and the modified metal traps baited with live male $R$. ferrugineus and coconut petioles (ANOVA, $\mathrm{P}<0.05$ ). A total of 52 adult $R$. ferrugineus was captured in modified metal traps $(n=4)$ and 67 weevils were captured in open plastic bucket traps $(n=4)$ for a period of 8 weeks.

There was a significant difference between the sexes of $R$. ferrugineus caught in these traps. Of the total weevils caught in plastic bucket traps, $62.6 \%$ were females and only $37.4 \%$ were males. Also in the modified metal traps $59.6 \%$ were females and $40.4 \%$ were males (ANOVA, $\mathrm{P}<0.05$, chisquare $=5.74$ ).

\section{Field stability of ferrugineol}

Field stability of ferrugineol and the capture rates of pheromone traps were determined in this experiment. Table 1 shows the mean capture rates of ferrugineol traps in 4 different study sites from August - October 1996. A total of 373 adult weevils were caught in 5 ferrugineol traps from Dummalasooriya and 120 adult weevils from Thummodara during first 9-: weeks. These plantations had high incidence of red weevil damage before trapping. In Badalgama plantation, where the damage incidence was moderate, a total of 116 weevils were caught by 5 ferrugineol traps in 9 weeks whereas in Nattandiya plantation where the damage incidence was low, a total of 81 weevils were caught. Total capture rates varied in 4 experimental sites according to the severity of the initial damage incidence (Table 1). Mean capture rate decline to $<1$ weevil/trap/week in Nattandiya, Badalgama and Thummodara study sites after 12 weeks of trapping. However in Dummalasooriya the mean capture rate remained at $>1$ weevils/trap/week even after 12 weeks. But in all sites no significant trap catches were observed after 12 weeks of trapping.

Fig. 2 shows the damage incidence in different study sites before and during pheromone trapping. In all sites sharp reduction of damage incidence was observed during trapping. In all sites there was a $\sim 50 \%$ reduction of damage after one month of trapping. Even in Dummalasooriya, where the initial damage incidence was very high, number of infested palms declined to i palm per 10- ha block after 3-months of trapping. 
Table 1: Mean capture rates of ferrugineol baited bucket traps in 4 experimental sites over 12 weeks

\begin{tabular}{rcccc}
\hline Week & \multicolumn{5}{c}{ Location } \\
\hline & Nattandiya & Badalgama & Thummodatra & Dummalasooriya \\
\hline 1 & 1.3 & 1.6 & 3.6 & 5.2 \\
2 & 4.3 & 6.0 & 3.4 & 3.4 \\
3 & 3.6 & 3.4 & 3.6 & 4.8 \\
4 & 1.3 & 2.8 & 3.4 & 5.8 \\
5 & 1.7 & 4.2 & 0.6 & 8.8 \\
6 & 1.7 & 0.8 & 3.0 & 6.6 \\
7 & 3.0 & 2.4 & 2.8 & 4.4 \\
8 & 3.0 & 0.0 & 2.8 & 11.0 \\
9 & 0.0 & 0.0 & 0.8 & 8.8 \\
10 & 2.3 & 0.0 & 0.0 & 8.6 \\
11 & 2.7 & na & 0.0 & 6.2 \\
12 & 0.6 & na & 0.0 & 2.0 \\
\hline
\end{tabular}

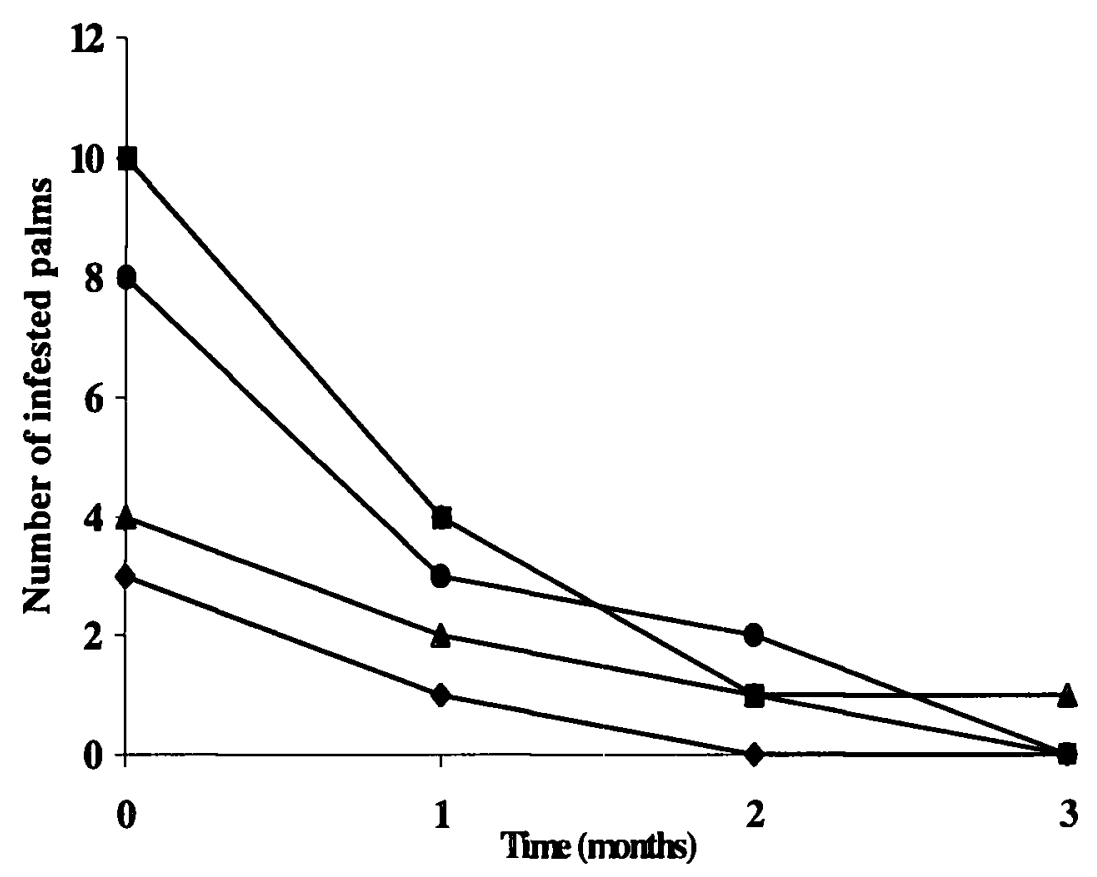

- $\rightarrow$-Dummlasooriya $\rightarrow-$ Thummdura $\rightarrow-$ Bexdalgama $\rightarrow-$ Nentandiya

Figure 2: Number of coconut palms damaged by $R$. ferrugineus in four 10-hectare experimental sites before and during trapping 


\section{DISCUSSION}

Palm weevils are known to be attracted to damaged or dying palms, split palm trunks and fermenting sap (Rochet et al, 1991). In Sri Lanka split coconut petioles have been used in a metal trap to catch red palm weevils. The catches of these traps were always low and the attraction of coconut petioles declined rapidly due to rotting. Replacement of petioles was necessary at least once a week and this operation was practically difficult. Also the high cost involved in the metal trap (Rs. 700/=) limited it use. Preliminary field studies have shown that the red weevils are much more attracted to the major component of the synthetic aggregation pheromone (Hallet et al., 1993, Gunawardena and Bandarage, 1995). Further work was felt necessary to confirm the efficacy of the technique as a pest management strategy.

Amongst the three trap designs baited with ferrugineol-pentanol bait, open plastic bucket traps were significantly more effective than the other designs. The apparent difference of weevil's attraction to these traps solely depend on their design. Capture by the bucket and funnel traps requires a flying response of weevils whereas capture by metal traps requires flying followed by landing and crawling. During the trapping we observed the behavior of adult weevils for 3 consecutive days. We observed that the weevils approaching traps gradually flew $1.5-2 \mathrm{~m}$ above the ground until they landed on the traps or in the vicinity of traps. The traps hung on palm stems at $1.5 \mathrm{~m}$ were in easy access for flying weevils. This may be the reason for the higher number of weevils caught in open plastic bucket traps and funnel traps hung at $1.5 \mathrm{~m}$ height than the metal traps, which were placed on the ground. Also in the open plastic bucket the bait was suspended on the rim of the bucket, and it was fully exposed to the environment. Therefore, the pheromone odour from the bait could be easily carried away by the wind. But in the funnel and the metal trap the bait was suspended inside the funnel and the inner metal tray respectively. These designs would interrupt the dispersion of the pheromone odour, thus making the bait less attractive for weevils. Also the weevils after perceiving the pheromone odour would directly fly to the open bucket traps and land on the rim. When they attempt to search the pheromone in a state of confusion the weevils easily slip into the soap water inside the trap and drowned. However, in funnel and the metal traps the weevils come searching for the pheromone, land on the surface of the funnel and the metal tray. During their attempt to find the pheromone, there is a chance for them to fly away instead of going into the trap. Therefore, the open bucket trap is the most appropriate trap design to be baited with ferrugineol. High capture rates, simplicity and ease of handling of these open bucket traps led us to use this trap for subsequent experiments as a standard trap. Also compared to the high cost metal trap the open plastic bucket trap would cost only Rs.100/=. Therefore, we conclude that the open bucket pheromone trap 
would be the most suitable replacement for the previously used metal trap for trapping adult $R$. ferrugineus.

The high attraction of female weevils to ferrugineol-pentanol traps were significant in all of these experiments. This is contrary to the report by Hallet et al 1993, who found no sex difference in ferrugineol baited traps. Although we cannot explain the apparent difference in the behaviour of sexes, we reasoned that the high attraction of fernale weevils for the pheromone may be due to the fact that they use the odour of the aggregation pheromone in combination with pentanol as a signal for finding both their oviposition and feeding sites. Female $R$. ferrugineus is a prolific egg layer and lay fertile eggs throughout their $\sim 3$ months lifespan (Rajapakse and Kanagaratnam, 1988). Therefore, ferrugineol baited traps can be effectively used to arrest the population growth of this pest in a given area in a given time.

Because $R$. ferrugineus is a very active insect the question arose as to possible interference between treatments. In our study the distance between two traps was $50 \mathrm{~m}$. We assumed that this distance was adequate to minimise the interference between treatments. However. Oehlschlager et al (1993) suggested if there were low numbers of insects in the experimental sites and two traps were installed in close proximity, capture rates might be lower than if they are separated by a longer distance. Therefore, we think that this aspect needs further investigation.

The results of the experiment on comparison of traps revealed that there is no difference in the capture rates of adult weevils in ferrugineolcoconut petiole baited open bucket traps and the modified metal trap baited with live males and coconut petioles. In the modified metal trap, live male weevils produced the natural blend of the aggregation pheromone and fresh coconut petioles provide necessary host plant volatiles. Ferrugineol in the open bucket traps attracted as much weevils as the natural pheromone blend did. The use of a synthetic form of the aggregation pheromone assumes that an insect behaves as though it has perceived the odour of the natural pheromone. The results of this experiment evidently showed that ferrugineol fits for this assumption.

Mean weevil counts in standard bucket traps baited with ferrugineol in different plantations varied considerably with time. Environmental factors such as temperature, prevailing wind speed and direction and rainfall are known to affect the numbers of insects caught in pheromone traps (Janson et al. 1989). In Nattandiya, Badalgama and Thummodara where the initial - infestation was recorded as low, moderate and.high respectively the mean capture rate declined to $<1$ weevil per trap per week while in Dummalasooriya where the initial red weevil infestation was very high, it was $>1$ weevil per 
trap per week after 12 weeks of trapping. This lower capture rate was attributed to decline in the release rate of ferrugineol as it aged. In all sites ferrugineol bait was almost exhausted after 12 weeks. But in Dummalasooriya even with the very low release rate the higher mean capture rate may be due to the very high resident weevil population in this plantation. However, we concluded that the effective life span of $22 \mathrm{mg}$ of ferrugineol at a release rate of $0.3-0.5 \mathrm{mg}$ per day was $9-12$ weeks in field conditions $\left(30 \pm 2^{\circ} \mathrm{C}\right.$ and $75 \pm$ 5\% R.H.).

Reduction of the red weevil damage incidence in these study sites coincided with the capture rates in ferrugineol traps. As we expected, at least some of these weevils caught in traps were from the second generation weevils emerging from intact infested palms and the others were from immigrating weevils from adjacent areas. Dissection of few captured weevils revealed that they were gravid females. Red weevil adults mate soon after emerging from pupal cocoons and it is likely that in the presence of suitable hosts, females will lay their eggs as soon as possible after mating (Rajapakse and Kanagaratnam, 1988). Therefore, we expected the damage incidence to increase if the weevil population remained unchecked. Because the damage incidence was recorded over only 3 -month period, we have no evidence to suggest the appropriate interval required for the appearance of new cases of damaged palms.

We observed the trap catch in the pheromone traps situated along the boundaries of experimental sites were always higher than the traps in the interior of the experimental blocks. Oehlschlager et al, 1995 reported same observations for $R$. Palmarum in oil palm plantations. These weevils caught in the boundaries were either immigrants from adjoining coconut plantations or emigrants attracted back at the boundaries. Pheromone based mass trapping has been used successfully for reducing population of $R$. Palmarum of coconut plantations in south America (Oehlschlager et al., 1995) and for disrupt mating behaviour of Scirpophaga incertules of rice fields in India (Cork et al., 1996). Our study also suggest the usefulness of the synthetic aggregation pheromone of red palm weevil as a pest management tactic. In plantations heavily infested with $R$. ferrugineus, continuos trapping of weevils with ferrugineol baited open bucket traps over a period of time, significantly lowered the infestations which in turn reduced the use of insecticides. Therefore, using of ferrugineol baited traps in integrated management programs of the red palm weevil would also be cost effective.

\section{ACKNOWLEDGMENTS}

We would like to acknowledge the assistance provided by the Vice Chancellor and the Head of the Department of Chemistry of the University of 
Kelaniya for permission to use the laboratory facilities. Thanks are also due to Messrs. Niranjith Perera, Nishan Senaviratne and Noel Fernando for assisting with field application and data collection. Dr. T S G Peris is specially thanked for analyzing of data. The authors are particulariy thankful to the estate owners whose participation and interest enabled us to undertake these study on their lands. Part of this work was funded by the Council for Agricultural Research Policy Sri Lanka.

\section{REFERENCES}

Cork, A., De Souza K., Krishnaiah, K., Kumar, D.V.S.S.R., Reddy, A.A and Casagrande, E (1996). Control of yellow stem borer, Seirpophaga incertulas (Lepidoptera: Pyralidae) by mating disruption on rice in India: effect of natural pheromone blends and application time on efficacy. Bulletin of Entomological Research 86: 515-524.

Gunawardena, N.E. and Bandarage, U.K. (1995). 4-methyl-5-nonanol (ferrugineol) as an aggregation pheromone of the coconut pest, Rhynchophorus ferrugineus $\mathrm{F}$. (Coleoptera: Curculionidae) : Synthesis and use in a preliminary field assay. J. Natn. Sci. Coum. Sri Lanka. 23(2): 7179.

Gunawardena, N.E. and Herath, H.M.W.K.B. (1995). Enhancement of the activity of ferrugineol by $\mathrm{N}$-pentanol in an attractant baited trap for the coconut pest, Rhynchophorus ferrugineus F. (Coleoptera: Curculionidae). J. Natn. Sci. Coun. Sri Lanka. 23(2): 81-86.

Hallet, R.H., Gries, G., Gries, R., Borden, J.H., Czyzewska, E., Oehlschlager, A.C., Pierce, H.D (Jr)., Angerilli, N.P.D. and Rauf. A., (1993). Aggregation pheromone of two Asian palm weevils, Rhynchophorus ferrugineus and $R$. vulneratus. Naturwissenschaften 80: 328-331.

Janson, R.K., Heath, R.R and Coffeit, J.A (1989). Temporal and spatial patterns of sweet potato weevil (Coleoptera: Curculionidae) counts in pheromone baited traps in white-fleshed sweet potato fields in southern Florida. Environ Entomol. 18: 691-697.

Mahindapala, R. (1993). Integrated management of red palm weevil. CARPGTZ, Agricultural Research Management Project. Discussion document 2: $35-41$.

Nirula, K.K. (1996). Investigations on the pests of coconut palm. Indian cocon. J 10(1): 28-40. 
Oehlschlager, A.C., McDonald, R.S., Chinchilla, C.M., and Patschke, N.S. (1995). Influence of a pheromone-based mass-trapping system on the distribution of Rhynchophorus Palmarum (Coleoptera: Curculionidae) in oil palm. Environ. Entomol. 24(5): 1005-1012.

Oehlschlager, A.C., Chinchilla, C.M., Gonzalez, L.M., Jiron, L.F., Mexzon, R., and Morgan, B. (1993). Development of a pheromone-based trapping system for Rhynchophorus palmarum (Coleoptera: Curculionidae). J. Econ.Entomol. 86(3): 1381-1392).

Perera, P.A.C.R. (1990). New trap for control red palm weevil. Annual Report of the Crop Protection Division, Coconut Research Institute of Sri Lanka.

Rajapakse, C.N.K and Kanagaratnam, P. (1988). Further observations on the red palm weevil pest. Coconut Bulletin. (2): 20-22.

Rochet, D., Gonzalez, V.A., Mariau, D., Villanueva, G.A and Zagatti, P. (1991). Evidence for a male produced aggregation pheromone in the American palm weevil, Rhynchophorus palmarum L. (Coleoptera: Curculionidae). J. Chem. Ecol. 17: 1221-1230. 